06

\title{
Влияние частоты вращения дискового подложкодержателя на кристаллоструктурные характеристики слоев арсенида галлия, формируемых в процессе MOCVD эпитаксии
}

\author{
() П.Б. Болдыревский, ${ }^{1}$ Д.О. Филатов, ${ }^{1}$ И.А. Казанцева, ${ }^{1}$ М.В. Ревин, ${ }^{1}$ Д.С. Смотрин, ${ }^{1}$ П.А. Юнин ${ }^{2}$ \\ ${ }^{1}$ Нижегородский государственный университет им. Н.И. Лобачевского, \\ 603950 Нижний Новгород, Россия \\ ${ }^{2}$ Институт ффизики микроструктур РАН, \\ 603950 Нижний Новгород, Россия \\ e-mail: bpavel2@rambler.ru
}

(Поступило в Редакцию 24 июня 2017 г.)

Изучено влияние частоты вращения дискового подложкодержателя на механизм роста и кристаллоструктурные характеристики слоев арсенида галлия, формируемых в процессе газофазной эпитаксии с использованием металлоорганических соединений и гидридов (MOCVD). Установлены зависимости скорости и механизма роста, общей степени совершенства кристаллической структуры слоев при изменении частоты вращения от 0 до $400 \mathrm{rpm}$.

DOI: 10.21883/JTF.2018.02.45411.2405

\section{Введение}

Газофазная эпитаксия с использованием металлоорганических соединений и гидридов в качестве исходных веществ (MГЭ/MOCVD), наряду с молекулярно-лучевой эпитаксией (МЛЭ/MBЕ), является основным технологическим процессом формирования нано-гетероструктур полупроводниковых соединений $\mathrm{A}_{3} \mathrm{~B}_{5}$, перспективных материалов СВЧ- и оптоэлектроники [1-3]. В целом основные кинетические характеристики MOCVD эпитаксиальных процессов арсенида и нитрида галлия достаточно хорошо изучены, что обеспечивает их промышленное применение. Однако повышение характеристик современных полупроводниковых приборов определяет необходимость уточнения и развития конструкторскотехнологических параметров эпитаксиальных систем и исследования их влияния на свойства слоев. Стандартным технологическим приемом эпитаксиального процесса является вращение подложки, расположенной на вращающемся дисковом подложкодержателе. Для высокопроизводительных реакционных камер применяется планетарное вращение. Необходимость использования вращающихся подложкодержателей обусловлена требованиями получения приборных структур с минимально возможным разбросом толщины эпитаксиальных слоев по площади подложки. При этом вращение дискового подложкодержателя оказывает определенное влияние на газодинамику и массоперенос в зоне осаждения, что, в свою очередь, должно оказывать заметное влияние на механизм роста и свойства эпитаксиальных слоев. В известной литературе отсутствуют данные по систематическому изучению эффектов, связанных с вращением дискового подложкодержателя в процессах MOCVD эпитаксии.
Целью настоящей работы является сравнительное изучение морфологии поверхности и степени совершенства кристаллической структуры гомоэпитаксиальных слоев арсенида галлия при изменении частоты вращения дискового подложкодержателя от 0 до $400 \mathrm{rpm}$.

\section{1. Экспериментальная часть}

Эпитаксиальное наращивание слоев GaAs проводили на модернизированной установке Epiquip VP502-RP, снабженной горизонтальной реакционной камерой (вектор линейной скорости потока газовой смеси на входе в зону осаждения параллелен плоскости подложки) и индукционным нагревом вращающегося дискового подложкодержателя. Использовалось газодинамическое вращение подложкодержателя отдельным потоком водорода c регулируемой объемной скоростью $0-600 \mathrm{~cm}^{3} / \mathrm{min}$, что обеспечивало соответствующий диапазон частоты вращения 0-400 rpm. Эпитаксиальное наращивание проводили на стандартных подложках $\mathrm{GaAs}$ диаметром 2 inch с кристаллографической ориентацией (100), разориентированных на $2^{\circ}$ к (111)A. Концентрацию триметилгаллия $\left(\mathrm{Ga}\left(\mathrm{CH}_{3}\right)_{3}\right)$ в потоке газовой смеси поддерживали постоянной $\left(C_{\mathrm{Ga}\left(\mathrm{CH}_{3}\right)_{3}}=0.07 \mathrm{mmol} / \mathrm{min}\right)$. Превышение концентрации арсина в потоке газовой смеси составляло $C_{\mathrm{AsH}_{3}} / \mathrm{C}_{\mathrm{Ga}\left(\mathrm{CH}_{3}\right)_{3}} \approx 40$. Перед началом процесса осаждения проводили отжиг подложек в реакционной камере при температуре эпитаксии в атмосфере газа-носителя (водород) и арсина $\left(\mathrm{AsH}_{3}\right)$ в течение 5 min. Экспериментальные образцы получали при общем пониженном на порядок давлении в газовой фазе реакционной камеры $\left(p=10^{4} \mathrm{~Pa}\right)$, что соответствует основным режимам получения приборных структур. Профили распределения толщин слоев по диаметру образцов измерялись с помощью системы Talysurf CCI 2000 (интерфе- 
рометр белого света). Погрешность измерений не превышала $\pm 1.0 \mathrm{~nm}$ [4]. Общее кристаллоструктурное совершенство эпитаксиальных слов толщиной $700-900 \mathrm{~nm}$ оценивалось методом двухкристальной рентгеновской дифрактометрии на дифрактометре Bruker D8 Discover. Кривые качания снимались с круглым коллиматором, формирующем пучок диаметром около $1 \mathrm{~mm}$, в симметричной геометрии и в геометрии скользящего падения, что обеспечивает соответствующую глубину проникновения пучка. Ошибку измерений можно оценить как $\pm 0.0005 \mathrm{deg}$.

Для исследования морфологии поверхности на начальных стадиях эпитаксиального роста использовали метод атомно-силовой микроскопии (АСМ) в контактном режиме постоянной силы. Исследования проводились при комнатной температуре в атмосферных условиях на установке NT-MDT (Россия), состоящей из контроллера Integra и сканирующей головки Smena A, оснащенной емкостными датчиками перемещения ACM зонда. Использовались кремниевые АCM зонды производства компании NT-MDT марки CSG-01 с радиусом кривизны острия зонда $R_{p} \approx 10 \mathrm{~nm}$. Паспортное значение относительной неопределенности измерений координат в плоскости поверхности образца $x, y$ в области $1 \mu \mathrm{m}<x, y<100 \mu \mathrm{m}$ при включенных емкостных датчиках перемещения зонда составляло не более $1 \%$. Датчик перемещения зонда по высоте (координата $z$ ) отключался, поскольку перепады высот на поверхности исследуемых образцов составляли $<10 \mathrm{~nm}$, а в этом диапазоне высот использование емкостного датчика приводило к недопустимо большой неопределенности измерения по координате $z$ (до $100 \%$ и более). Относительная неопределенность измерения координаты $z$ в режиме измерений с отключенным емкостным датчиком перемещений составляла $<5 \%$.

\section{2. Результаты и обсуждение}

На рис. 1 приведена зависимость скорости эпитаксиального роста от частоты вращения дискового подложкодержателя $\omega$. Кривая имеет немонотонный характер.

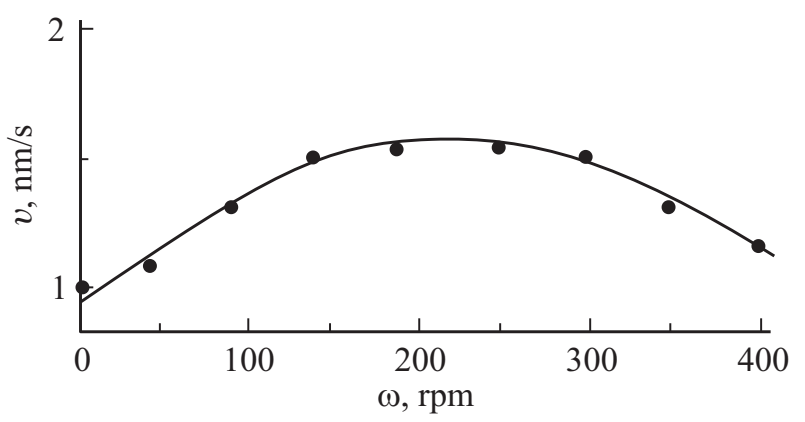

Рис. 1. Зависимость скорости роста эпитаксиальных слоев арсенида галлия $(v)$ от частоты вращения дискового подложкодержателя $(\omega)$. Температура эпитаксии $-620^{\circ} \mathrm{C}$.

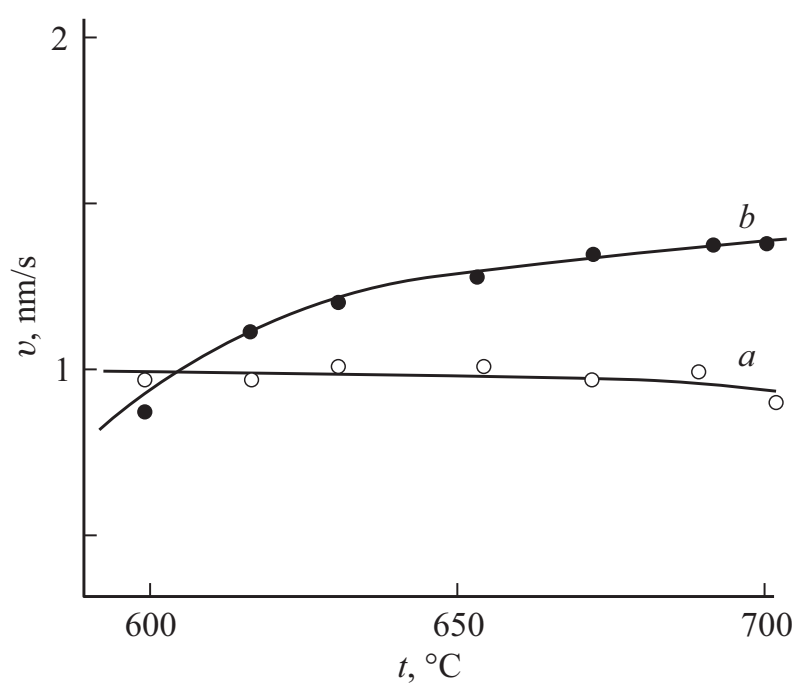

Рис. 2. Температурная зависимость скорости роста эпитаксиальных слоев, $\omega: a-100, b-350 \mathrm{rpm}$

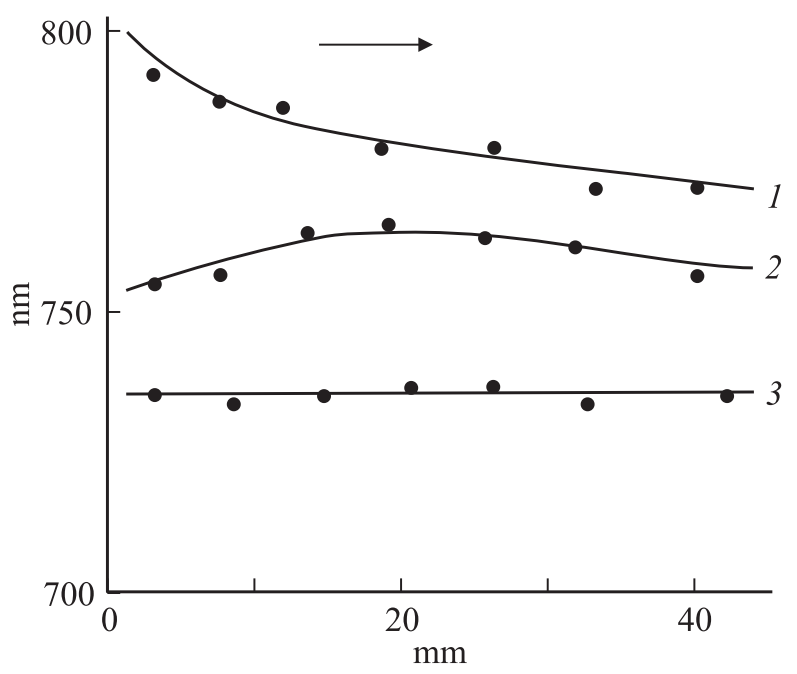

Рис. 3. Профили распределения толщины эпитаксиальных слоев вдоль диаметра подложки, $\omega: 1-0,2-20,3-60 \mathrm{rpm}$. Стрелка показывает направление потока газовой смеси.

Принимая, что процесс осаждения эпитаксиальных слоев лимитируется диффузионным массопереносом $[5,6]$, можно объяснить увеличение скорости роста при повышении частоты вращения до $200 \mathrm{rpm}$ соответствующим уменьшением толщины диффузионного слоя у поверхности подложкодержателя.

О протекании процесса эпитаксии в диффузионном режиме свидетельствуют отсутствие зависимости скорости роста от температуры в интервале $600-700^{\circ} \mathrm{C}$ (рис. $\left.2, a\right)$ и ее линейная зависимость от концентрации $\left(\mathrm{Ga}\left(\mathrm{CH}_{3}\right)_{3}\right)$. В этом случае, скорость эпитаксиального роста $v$ можно оценить по формуле [5]

$$
v \sim \frac{D}{\rho \delta} C_{\mathrm{Ga}\left(\mathrm{CH}_{3}\right)_{3}},
$$



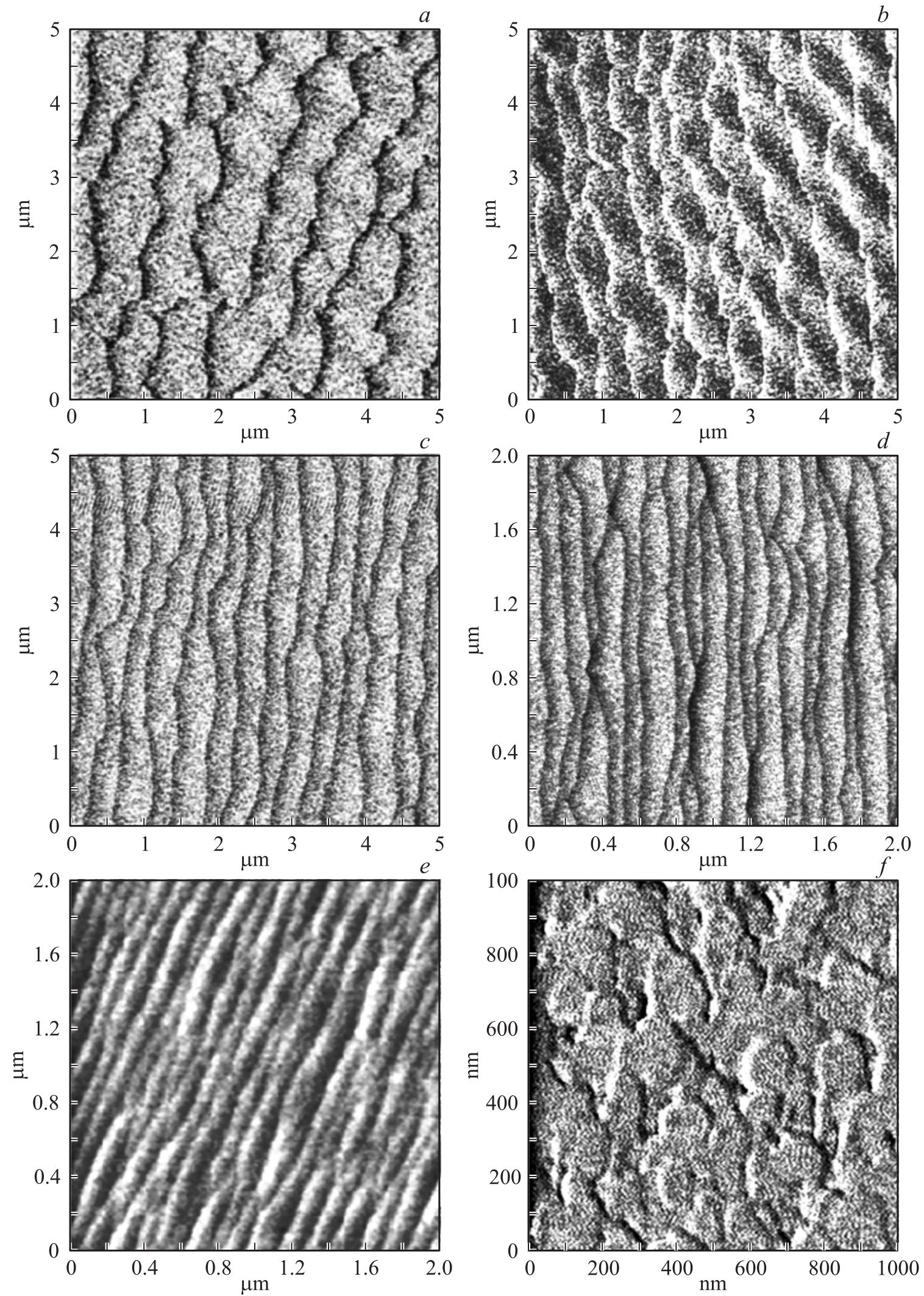

Рис. 4. АCM изображения поверхности эпитаксиальных слоев GaAs на начальных стадиях роста. Частота вращения подложки $\omega, \mathrm{rpm}: a-c-0 ; d-60 ; e-100 ; f-350$. Расстояние от переднего края подложки, $\mathrm{mm}: a-5 ; b-15 ; c-45$. 
Результаты рентген-дифракционных исследований эпитаксиальных слоев, полученных при различных частотах вращения подложкодержателя

\begin{tabular}{c|l|c|c|c|c|c|c}
\hline \multicolumn{2}{c|}{ Частота вращения $\omega}$, & 0 & 60 & 100 & 150 & 200 & 400 \\
\hline rpm & $\begin{array}{l}\text { (004)s-отражение } \\
\text { в симм. геометрии }\end{array}$ & 0.057 & 0.0063 & 0.0060 & 0.0059 & 0.0060 & 0.0063 \\
\cline { 2 - 7 } $\begin{array}{c}\text { Ширина } \\
\text { кривой } \\
\text { качания } \\
(\text { FWHМ }), \\
\text { deg }\end{array}$ & $\begin{array}{l}\text { (044)-отражение } \\
\text { в геометрии } \\
\text { скользящего } \\
\text { падения }\end{array}$ & 0.010 & 0.011 & 0.011 & 0.012 & 0.017 & 0.026 \\
\end{tabular}

и толщина диффузионного слоя $\delta$, как следует из решения уравнения конвективной диффузии, определяется выражением [6]

$$
\delta=1.6\left(\frac{D}{v}\right)^{1 / 3} \sqrt{\frac{v}{\omega}},
$$

где $D-$ коэффициент диффузии частиц ростового вещества, $\rho$ - плотность арсенида галлия, $v-$ кинематическая вязкость газовой среды.

Однако в области высоких частот вращения проявляется заметная температурная зависимость скорости роста (рис. 2, $b$ ), что свидетельствует о проявлении кинетики поверхностных процессов встраивания и упорядочивания частиц ростового вещества. В данном случае соотношение (1) становится неприменимым. Таким образом, достаточно сильное уменьшение толщины диффузионного слоя в области частот вращения диска свыше $200 \mathrm{rpm}$ определяет сдвиг процесса осаждения эпитаксиальных слоев в кинетическую область и соответствующее уменьшение скорости роста.

На рис. 3 представлены профили распределения толщин эпитаксиальных слоев по диаметру структуры. Клиновидный профиль (рис. 3, кривая 1) в целом соответствует форме пограничного и диффузионного слоев при обтекании газовым потоком плоской пластины при отсутствии вращения диска [7]. Близкая к оптимальной однородность толщин слоев (разброс значений не превышает $2 \mathrm{~nm}$ ) достигается при частотах вращения $\sim 60 \mathrm{rpm}$ (рис. 3 , кривая 3 ) и заметно не изменяется при дальнейшем увеличении скорости вращения.

На рис. 4 приведены АСМ изображения поверхности эпитаксиальных слоев на начальных стадиях роста (время осаждения $5 \mathrm{~s}$ ). При отсутствии вращения диска наблюдается слоисто-ступенчатый механизм роста с изменением плотности и высоты ступеней на растущей поверхности вдоль направления потока газовой смеси (рис. $4, a-c)$. АСМ изображения получены путем регистрации сигнала атомно-силового сенсора [8]. Такой способ визуализации данных АСМ предпочтителен для представления морфологии поверхности образцов, исследованных в настоящей работе, поскольку при данном способе визуализации подчеркиваются резкие изменения высоты поверхности образцов, характеризующихся в целом весьма малыми перепадами высот (например, края макроступеней роста). Неоднородность распределения параметров системы ступеней по поверхности связана с изменением толщины диффузионного слоя при обтекании плоской пластины газовым потоком. Так, вблизи переднего края подложки (рис. 4,a) наблюдается система макроступеней, высотой $h$ в два монослоя GaAs ( $h \approx 0.565 \mathrm{~nm}$ в направлении $(001))$. С противоположного конца подложки (рис. 4,c) наблюдается регулярная система монослойных ступеней роста. Соответственно средняя ширина ступеней на рис. 4, $c$ приблизительно вдвое меньше, чем на рис. 4, $a$. Наибольший интерес представляет морфология переходной области между вышеуказанными двумя областями (рис. $4, b$ ). На рис. 4, $b$ видно, что переход от режима роста с образованием двухмонослойных макроступеней (рис. $4, a$ ) к слоисто-ступенчатому росту с образованием монослойных ступеней (рис. 4,c) происходит путем распада двухмонослойных ступеней на две монослойные с образованием характерного периодического муар-узора с выделенным направлением, составляющим угол $\approx 45^{\circ}$ с направлением ориентации подложки.

Наиболее регулярные квазипериодические системы макроступеней роста наблюдаются при частотах вращения 60-100 rpm (рис. 4, d,e). При увеличении скорости вращения диска более $200 \mathrm{rpm}$ на поверхности эпитаксиальных слоев наблюдаются островки высотой 1-3 nm (рис. $4, f)$. Таким образом, при соответствующем увеличении $\omega$ происходит постепенный переход от слоистоступенчатого механизма роста эпитаксиальных слоев к островковому и от диффузионного режима осаждения к кинетическому.

В таблице приведены значения ширины кривых качания для образцов, выращенных при различной частоте вращения дискового подложкодержателя.

Все образцы имели монокристаллическую структуру. Однако, судя по ширине кривых качания, при частотах вращения более $150 \mathrm{rpm}$ наблюдается некоторое снижение общего структурного совершенства эпитаксиальных слоев, что связано с проявлением островкового механизма роста. Результаты съемки кривых качания в симметричной геометрии (глубина проникновения 
пучка $\sim 10 \mu \mathrm{m})$ свидетельствуют о примерно одинаковом качестве подложечного материала, используемого в экспериментах.

\section{Заключение}

Представленные в настоящей работе результаты показывают, что в эпитаксиальных MOCVD процессах необходимо учитывать и оптимизировать такой параметр, как частота вращения дискового положкодержателя, что обеспечивает получение полупроводниковых слоев с наиболее высоким качеством кристаллической структуры и морфологии поверхности. Для данной эпитаксиальной системы близкую к оптимальной область частот вращения можно оценить как 60-100 rpm.

АCM измерения выполнены с использованием оборудования центра коллективного пользования - Научнообразовательного центра „Физика твердотельных наноструктур“ Нижегородского государственного университета им. Н.И. Лобачевского.

\section{Список литературы}

[1] Molecular Beam Epitaxy and Heterostructures / Ed. by L.L. Chang, K. Ploog. Amsterdam: Martimus Nijhoff, 1985. $700 \mathrm{p}$.

[2] Herman M.A., Richter W. Epitaxy-Physical Principles and Technical Implementation. Berlin: Sitter, Springer, 2004. 507 p.

[3] Stringfellow G.B. Organometallic Vapor-phase Epitaxy: Theory and Practice. Boston: Academic Press, 1999. 572 p.

[4] Болдыревский П.Б., Коровин А.Г., Денисов С.А., Светлов С.П., Шенгуров В.Г. // ЖТФ. 2014. Т. 84. Вып. 11. C. $155-158$.

[5] Болдыревский П.Б., Хрыкин О.И. // Изв. АН СССР. Неорганические материалы. 1990. Т. 26. № 10. С. 2215-2217.

[6] Панкратов Е.Л., Болдыревский П.Б. // ПМТФ. 2016. Т. 57. № 4. C. 74-83.

[7] Левич В.Г. Физико-химическая гидродинамика. М.: Физматгиз, 1962. 699 с.

[8] Garcia R., Perez R. // Surf. Sci. Report. 2002. Vol. 47. P. 197-301. 